\title{
Insularity forcing on plant persistence strategies in edaphic island systems
}

Luisa Conti ${ }^{1,2}$, Francisco E. Méndez-Castro ${ }^{2}$, Milan Chytrý ${ }^{3}$, Lars Götzenberger ${ }^{2,4}$, Michal Hájek $^{3}$, Michal Horsák ${ }^{3}$, Borja Jiménez-Alfaro ${ }^{5}$, Jitka Klimešová ${ }^{2,6}$, David Zelený ${ }^{7}$, Gianluigi Ottaviani $^{2}$.

${ }^{1}$ Faculty of Environmental Sciences, Czech University of Life Sciences, Prague, Czech Republic

${ }^{2}$ Institute of Botany, The Czech Academy of Sciences, Třeboň, Czech Republic

${ }^{3}$ Department of Botany and Zoology, Faculty of Science, Masaryk University, Brno, Czech

Republic

${ }^{4}$ Department of Botany, Faculty of Science, University of South Bohemia, České Budějovice, Czech Republic

${ }^{5}$ Research Unit of Biodiversity (CSUC/UO/PA), University of Oviedo, Mieres, Spain

${ }^{6}$ Department of Botany, Faculty of Science, Charles University, Prague, Czech Republic

${ }^{7}$ Institute of Ecology and Evolutionary Biology, National Taiwan University, Taipei, Taiwan

\section{Corresponding author:}

Luisa Conti

Faculty of Environmental Sciences, Czech University of Life Sciences, Prague

luisa.conti@fzp.czu.cz

\section{Acknowledgements}

LC, FEMC and GO were supported by the Czech Science Foundation (GAČR Project 1914394Y). MHo was supported by the Czech Science Foundation project no. 19-01775S. MC and MHá were supported by the Czech Science Foundation project 19-28491X. LEMC, LG, JC and GO were also supported by the long-term research development project No. RVO 67985939 of the Czech Academy of Sciences.

Biosketch LC is a plant ecologist, mainly interested in abiotic, biotic, and geographical drivers of plant assembly. She has also explored drivers of species temporal stability and ecosystem functions, as well as invasions dynamics and their impacts. Particularly, she uses plant functional patterns to unravel these ecological processes. More recently, she has also been investigating remote sensing approaches for quantifying taxonomical and functional diversity. https://www.researchgate.net/profile/Luisa-Conti 
1 Insularity forcing on plant persistence strategies in edaphic island systems

3 Running title Insularity promotes plant persistence

\section{Abstract}

6 Aim: Trait-based approaches are increasingly implemented in island biogeography, providing

7 key insights into the eco-evolutionary dynamics of insular systems. However, what

8 determines persistence of plant species once they have arrived and established in an island

9 remains largely unexplored. Here, we examined links between non-acquisitive persistence

10 strategies and insularity across three terrestrial edaphic island systems, hypothesising that

11 insularity promotes strategies for local persistence.

12 Location: Europe: Western Carpathians, Moravia, and Cantabrian Range.

13 Time period: Present.

14 Major taxa studied: Vascular plants.

15 Methods: For each system, we used linear models at the island scale to test whether

16 persistence-related plant trait patterns (average trait values and diversity) depend on three

17 insularity metrics (island size, isolation and target effect). We focused on patterns of edaphic

18 island specialists because, in contrast to matrix-derived species, their presence is confined to

19 the edaphic islands.

20 Results: We found that insularity metrics explained large proportions in the variation of the

21 average and diversity of persistence-related traits of edaphic island specialists. Insularity was

22 associated with a decline in the proportion of island specialists that have clonal abilities, yet it

23 affected trait values of specialists towards enhanced abilities to persist locally (e.g. more

24 extensive lateral spread) while reducing trait variability. Higher degrees of insularity within

25 the systems were translated to stronger effects on functional trait patterns.

26 Main conclusions: Insularity affects plant species diversity, distribution and forms in

27 terrestrial island-like systems, similarly as it is assumed for true islands. Insularity -

28 measured using a single (island size, isolation) or combined (target effect) predictors - may

29 operate selecting for enhanced and less diverse persistence strategies. Ultimately, this

30 process, which we call insularity forcing, operates as a selective process to promote species

31 ability to avoid local extinction and to persist on terrestrial islands.

33 Keywords: functional diversity, island biogeography, island size, isolation, plant functional

34 traits, specialists, target effect 
35

36

\section{Introduction}

Plants have evolved a myriad of ecological strategies to survive in a vast range of environmental and geographical configurations (Díaz et al., 2016). One vital set of strategies are those related to the ability to persist in a given area, which allows plants to maintain viable populations and avoid local extinction (Klimešová, Martínková, \& Ottaviani, 2018). These strategies can be described by different plant traits linked to specific functions, such as investment into sexual and/or vegetative reproduction, dispersal of propagules, resprouting after disturbance, and space occupancy (and captured by clonal, bud-bank, seed traits and life forms, Klimešová et al., 2018; Ottaviani et al., 2020; Saatkamp et al., 2019; Violle, Navas, Vile, Kazakou, \& Fortunel, 2007; Weiher et al., 1999) While some of these functions are better studied, e.g. those associated with dispersal (Levin, Muller-Landau, Nathan, \& Chave, 2003), others, mainly those linked to clonal and bud-bearing organs, are regularly overlooked (Klimešová et al., 2018, 2019; Ottaviani, Martínková, Herben, Pausas, \& Klimešová, 2017). This is because sampling of these traits is generally more laborious and time-consuming (being associated with the belowground location of most organs) compared to more commonly used aboveground traits (e.g. leaf economics; Wright et al., 2004). This gap is common in plant ecology research at large, but it is particularly striking in studies focused on insular systems, where long-distance dispersal events are rare, and thus persistence strategies are key for ensuring population maintenance and avoid extinction (Ottaviani et al., 2020).

Compared to non-insular environments, insular systems often host endemic-rich, genetically and eco-morphologically distinct biota (Darwin, 1859; MacArthur \& Wilson, 1963, 1967; Burns, 2019; Carlquist, 1974) generated by the eco-evolutionary history associated with a limited spatial extent (König et al., 2021; Taylor, Weigelt, König, Zotz, \& Kreft, 2019). Insular systems are not restricted to oceanic islands but also include terrestrial island-like systems such as inselbergs, edaphic islands, and mountaintops (Harrison, Safford, Grace, Viers, \& Davies, 2006; Henneron, Sarthou, de Massary, \& Ponge, 2019; JiménezAlfaro, García-Calvo, García, \& Acebes, 2016). For plant specialist species of terrestrial island-like systems, these distinct patches in the landscape may operate as islands because the surrounding matrix is generally inhospitable to their establishment, similarly to water for true islands (Horsák et al., 2012; Ottaviani et al., 2020). Because of the specific spatial configuration of insular systems, island biogeographic studies have typically focused on colonisation (and related dispersal abilities; Franklin et al., 2013; Taylor et al., 2019) and speciation processes (MacArthur \& Wilson, 1967; Warren et al., 2015). Less is known about persistence, which can be considered as the opposite of local extinction or extirpation 
69 (Auffret, Aggemyr, Plue, \& Cousins, 2017). Moreover, trait-based approaches that focus on

70 persistence abilities are virtually non-existent, and as a result, plant persistence strategies and related processes remain poorly understood in insular systems (Ottaviani et al., 2020).

Insularity effects depend on two main components, namely island size and isolation (MacArthur and Wilson, 1963; Lomolino, 2000; Mendez-Castro et al., in press). Island size is considered a key determinant of species richness, with larger islands typically containing more species than smaller ones (Lomolino, 2000b; Lomolino \& Weiser, 2001). Also, larger islands tend to have higher variation in geology, topography, and microclimate (hence habitat diversity), which can also contribute to higher species richness (Hortal, Triantis, Meiri, Thébault, \& Sfenthourakis, 2009; Keppel, Gillespie, Ormerod, \& Fricker, 2016). Spatial isolation relates mainly to species colonisation chances: islands located more distantly from their species source (i.e. mainland or neighbouring islands) are likely to receive fewer species than islands located closer to the species source (Carter, Perry, \& Russell, 2020; Warren et al., 2015). At the same time, species on more isolated islands, both true islands and terrestrial islands, are exposed to a higher risk of local extinction (Jiménez-Alfaro et al., 2021; Warren et al., 2015; Whittaker, Fernández-Palacios, Matthews, Borregaard, \& Triantis, 2017). Most research in recent years has focused on disentangling and quantifying the relative contribution of island size and isolation in shaping species diversity patterns (e.g. Weigelt and Kreft, 2013; Jacquet et al., 2017). This effort has provided many valuable insights for island biogeography, yet sometimes the effect of insularity might be only detected by considering the joint effect of island size and isolation working together (e.g. by the target effect) (Gilpin and Diamond, 1976, Mendez-Castro et al., in press).

The effect of insularity on island plants should be reflected in distinct patterns of

92 functional traits (Biddick, Hendriks, \& Burns, 2019; Burns, 2019; Carlquist, 1974; Taylor et 93 al., 2019). By examining trait patterns, we can gain insights into different plant strategies and 94 processes occurring in insular systems, including those promoting or hindering persistence 95 (Auffret et al., 2017). In this work, our primary aim is to explore whether and how strongly 96 plant persistence strategies (captured by clonal, bud-bank, seed traits and life forms) are 97 linked to insularity - to our knowledge, the first attempt of this kind. We do so by examining three steadily isolated terrestrial island-like systems in Europe characterised by distinct edaphic conditions contrasting with the surrounding landscape (hereafter edaphic islands).

100 We focus particularly on the persistence strategies of plant specialist species of these 101 systems. 
102 Based on a recent overview of the topic (Ottaviani et al., 2020), we expect that 103 enhanced abilities of plants to persist locally will be related to a higher degree of insularity 104 in terms of the individual and joint effect of island size and spatial isolation. Specifically, we 105 predict that with higher degrees of insularity, plant specialists of edaphic islands are 106 distinguished by: (H1) trait values and functional strategies indicating better ability to persist 107 locally, such as higher percentage of clonal species, longer-lived connections between 108 ramets, higher capacity of lateral spread, larger and better-protected bud-bank traits, and 109 heavier seeds; and (H2) less diversified persistence strategies, i.e. species sharing similar 110 functional trait values (reduced variability).

\section{Methods}

113 In brief, to test whether insularity drives persistence-related trait patterns, we used vegetation 114 data from three different edaphic island systems and joined them with functional trait data 115 obtained from available databases. For all the three systems, we computed, at the island level, 116 trait averages and functional diversity, as well as insularity metrics, namely island size, 117 isolation, and target effect (the ratio between isolation and island size; Mendez-Castro et al., 118 in press). We used linear models to explore the relationship between single functional indices 119 and each individual insularity predictor.

\section{Edaphic island systems and species selection}

122 We examined three different types of terrestrial island-like systems experiencing long-term 123 isolation. Namely, these are spring fens in the Western Carpathians, Czech Republic and 124 Slovakia (hereafter fens), rocky outcrops in the Třebíč region in Moravia, Czech Republic 125 (hereafter outcrops), and siliceous mountaintops in the Cantabrian Mountains, Spain 126 (hereafter mountaintops) (Figure 1). All the three systems are distinguished by patches of 127 distinct soils supporting specific vegetation types, which are different from the surrounding 128 landscapes. Therefore, they are considered edaphic islands. The target vegetation types were 129 i) treeless calcareous fens; ii) dry, shallow-soil acidophilous grasslands for outcrops; and iii) 130 alpine grasslands on acidic bedrock for mountaintops. The three systems, which differ in their 131 geographical extent and environmental conditions, comprise floras with different species 132 composition and species richness. An expert-based categorisation was carried out for 133 identifying specialist species (and matrix-derived species). The total number of specialist 134 species was 57 for fens, 29 for outcrops and 42 for mountaintops, whereas the total number 135 of matrix-derived species was 260 for fens, 175 for outcrops and 125 for mountaintops. 
136 For fens, one $4 \times 4 \mathrm{~m}$ vegetation plot was sampled at the centre of each fen, which

137 generally corresponds to the most homogeneous and best-preserved part of the edaphic 138 island. In addition, a full species list for each island was compiled by a census across each of

139 the edaphic islands so that a full species list for each island was assembled (Hájek et al., 140 2011; Horsák et al., 2012). For outcrops, vegetation data were collected by performing plot141 based surveys ( 4 plots of $0.5 \times 0.5 \mathrm{~m}$ at each island) and, also in this case, complemented by 142 a census. For mountaintops, a total of 284 vegetation plots with sizes between 10 and $50 \mathrm{~m}^{2}$ 143 were sampled on the target vegetation type (with varying number of sampling plots, 144 proportional to island size). We sampled 49 islands for fens, 20 islands for outcrops, and 25 145 islands for mountaintops. In all systems, we considered only species occurrence (presence or 146 absence data) at the island level in the analyses.

Persistence-related trait data and functional metrics

149 For all the species, we compiled functional trait data relative to persistence strategies from 150 databases, such as Pladias (Chytrý et al., 2021), CLO-PLA3 (Klimešová, Danihelka, Chrtek, 151 de Bello, \& Herben, 2017), BiolFlor (Klotz, Kühn, \& Durka, 2002) and LEDA (Kleyer et al., 152 2008). We gathered information on whole-plant strategies related to reproductive type and 153 belowground clonal and bud-bearing organs (Klimešová et al., 2019; Ottaviani et al., 2020; 154 Ottaviani et al., 2017; Weiher et al., 1999; Westoby, 1998) (Table 1). For the mountaintops' dataset, the number of species for which trait data was available was very low. Therefore, information on the clonal ability and life form of mountaintop species was gathered directly from field observations. Information on the reproductive type (i.e. whether a species can reproduce only sexually, only vegetatively or both) was used to calculate the percentage of clonal species on each edaphic island. We considered as clonal all species that can reproduce vegetatively. Species data summary and trait-data completeness within each study system are presented in Supporting Information Appendix S1.

Because we expected the effect of insularity to be more pronounced on specialists, which are confined to the edaphic islands (compared to matrix-derived species), we focused on functional metrics for these species (Horsáková, Hájek, Hájková, Dítě, \& Horsák, 2018;

165 Ottaviani et al., 2020). Therefore, we calculated unweighted trait averages and functional 166 diversity metrics for specialist species across the three systems. However, to qualitatively 167 assess differences in trait patterns between specialists and matrix-derived species, we also 168 calculated these metrics for the latter. All results related to matrix-derived species are reported in Appendix S2. For each island, we calculated trait average as the mean value for 
170 each quantitative (numerical) trait, namely depth of the belowground bud bank, lateral

171 spread, persistence of the clonal growth organ, seed mass, and size of the belowground bud 172 bank (Table 1). We calculated diversity by using the mean pairwise distance of the species' 173 traits. For quantitative (numerical) traits, we used Euclidean distance, while for qualitative 174 (discrete categorical) traits (Raukiaer life form, type of clonal growth organ), we used Gower 175 distance (Gower, 1971). In addition, we calculated the multi-trait mean pairwise distance, 176 considering all the traits and using the Gower distance.

Insularity metrics

179 We explored the effect of insularity, namely of island size, spatial isolation and their joint 180 effect on plant populations. Hence, we used three insularity metrics which proved to be the most important predictors (tested against other connectivity and network metrics) of edaphic

182 island specialist species richness in the same study systems (unpublished data). In detail, we 183 used 1) edaphic island size (hereafter 'island size'; $\mathrm{m}^{2}$ ), defined as the area of the target 184 vegetation type present on each island (which can correspond to the entire island area or part 185 of it); 2) distance to nearest species source (hereafter 'isolation'; m), measured as the distance of the target island to the nearest putative species source - one of the islands in the same system scoring above the third quartile of both its size and plant specialist species richness; and 3) target effect (a dimensionless property of islands generated by scaling the distance to the species sources by the island size), calculated as the natural logarithm of the ratio between isolation and the square root of the island size. High values of target effect indicate a lower chance of colonisation, hence a strong role of isolation and a high degree of insularity. Size and isolation were log-transformed to normalise these variables prior to the statistical

Statistical analyses

196 Because we were interested in exploring how persistence-related trait patterns depend on each insularity metric and because correlation tests on insularity metrics for each system identified collinearity issues (Supporting Information Appendix S3), we used each insularity metric as a single explanatory variable for each functional index in separate models. For each edaphic island system, we explained the variation in each of the functional indices, trait averages $(\mathrm{H} 1)$ and functional diversity $(\mathrm{H} 2)$ at the island scale through ordinary least-square linear models. Therefore, for each functional index, we calculated three different linear models, each containing the functional index as the response variable and a single insularity 
204 metric as the explanatory variable (predictor). The same models were fitted for the set of 205 functional metrics related to the matrix-derived species (Appendix S2). For each model, we 206 calculated standardised effect sizes and relative standard errors (to compare the effects across 207 single models), coefficient of determination $\mathrm{R}^{2}$ (explained variation, to measure the goodness 208 of fit), and p-value (significance of the coefficient). The linearity and homoscedasticity of the 209 relationships were assessed by visually inspecting the model residuals, and we revealed no 210 issues with those assumptions. Here, we focus mainly on strong $\left(R^{2} \geq 0.10\right)$ and robust 211 findings (based on the standard error of the model estimate, and in most cases, significant at 212 p-value < 0.05). However, trait-data coverage for mountaintops was considerably sparser 213 than for the other two systems. Here, data were available only for the percentage of clonal 214 species and life form diversity, which restricted our ability to investigate trait patterns in that 215 system. All statistical analyses were done using the R statistical software (version 4.0.3).

\section{Results}

218 We found significant functional patterns depending on insularity metrics across the three systems under study. However, the number and strength of the relationships varied depending on the type of index and the particular system. Generally, all the patterns found for specialist species were stronger and more numerous than matrix-derived species (Supporting Information Appendix S2).

In all three systems, the insularity predictors explained a considerable amount of variability in the models related to the percentage of clonal specialists (with $\mathrm{R}^{2}$ up to 0.56 ; Table 2). Generally, island size and target effect explained a higher proportion of variability compared to isolation. Island size had a positive effect on the percentage of clonal specialists, while isolation and target effect exerted a negative effect.

Regarding the other trait average values, we found that lateral spread was explained by all insularity metrics in both fens and outcrops, although with very low coefficients (Table 3). In particular, lateral spread was negatively affected by island size and positively by isolation and target effect. For fens, we also found that the belowground bud bank was deeper in more insular conditions, with island size having a negative effect and target effect having a positive effect on this trait (with a similar pattern also revealed for the size of the belowground bud bank; Table 3). For outcrops, we found that both persistence of the clonal growth organ and seed mass were influenced by insularity, with target effect negatively linked to the persistence of the clonal growth organ and island size negatively affecting seed mass. The amount of variability explained in these models was generally lower compared to 
238 the models regarding the percentage of clonal species and those regarding functional 239 diversity (with $\mathrm{R}^{2}$ up to 0.26 ; Table 3 ).

240 For functional diversity, we found stronger and more numerous significant patterns in 241 fens than in outcrops. We found that for both edaphic island systems, Raunkiaer life forms 242 (also confirmed in mountaintops), type of clonal growth organs, and multi-trait diversity were 243 explained by the insularity metrics (Table 4). Generally, these relationships were positively 244 explained by island size and negatively by isolation and target effect. In fens, diversity of size 245 and depth of the belowground bud bank, and for outcrops, lateral spread were largely 246 explained by all the insularity metrics (with $\mathrm{R}^{2}$ reaching up to 0.45 , and in most cases 247 between 0.15 and 0.30 ; Table 4), with a consistent pattern as of those highlighted above (i.e. 248 positive effect of island size, negative of isolation and target effect).

\section{Discussion}

251 Our results confirmed that insularity - measured as island size, isolation or target effect 252 largely affects functional trait patterns determining plant persistence strategies in edaphic 253 island systems (Klimešová et al. 2019; Ottaviani et al. 2020). Contrary to our expectation, the 254 percentage of edaphic-island specialist species that can reproduce vegetatively declined with 255 insularity. However, we did confirm that specialists experiencing a higher degree of 256 insularity were equipped with functional strategies (in terms of average trait values) that promote their local persistence, such as enhanced abilities to occupy space, higher resprouting vigour after biomass removal (and better-protected buds) and heavier seeds (Jiménez-Alfaro et al., 2016; Rossetto \& Kooyman, 2005). Additionally, these strategies appeared to be selected by insular conditions, i.e. more similar trait values shared across species in a given island, generating lower trait diversity. We also found that among the three studied edaphic island systems, the flora of the fen system was most affected by insularity.

Clonal specialists are less represented in more insular systems, yet they have enhanced abilities to persist locally

266 We consistently found that the percentage of clonal species specialised to the edaphic islands 267 declined with insularity across the three systems, so rejecting the first part of our H1. This 268 finding may be caused by a functional trade-off between vegetative reproduction and 269 dispersal abilities (Rossetto and Kooyman, 2005; Herben, Šerá and Klimešová, 2015), 270 influencing species occupancy in terrestrial edaphic islands. As a result, clonal species 271 (which account for a large proportion of specialists in all the studied systems: Table S1.2, 
272 Supporting Information) seem to be strongly limited in their dispersal. Therefore, clonal

273 specialists are less likely to reach more distant islands than non-clonal specialist species.

274 Conversely, non-clonal species may not follow this rule and rather than constrained by

275 dispersal, their distribution may be influenced by other biotic and abiotic factors. For

276 example, in fens, non-clonal species trait patterns may be largely determined by either biotic

277 interactions, such as competition between their seedlings and bryophytes (Singh et al., 2019),

278 or higher rates of local extinctions due to temporarily hostile environments (Horsák et al., 279 2012).

280 The second part of the first hypothesis - expecting that a high degree of insularity 281 promotes persistence strategies - was supported. Specialist species displayed trait values 282 indicative of better abilities to persist locally both in fen and outcrop systems (no data 283 available for mountaintops). These trait values included, for example, a more extensive 284 lateral spread, resulting in a higher ability to occupy the surrounding space and its resources, 285 and deeper buds belowground, thus better protected resprouting tissues. This finding implies 286 that edaphic island specialists in more insular conditions (smaller island size, more 287 pronounced isolation, or larger target effect) tend to employ strategies aimed at maximising 288 local persistence (Jiménez-Alfaro et al., 2016; Kavanagh \& Burns, 2014; Rossetto \& 289 Kooyman, 2005; Weber, VanDerWal, Schmidt, McDonald, \& Shoo, 2014). This can be 290 attained by i) producing heavier seeds (with limited dispersal), ii) better abilities to explore 291 and remain in the proximal area of the parent plant, and iii) enhanced resprouting capacities 292 after biomass removal (Ottaviani et al., 2020). Therefore, insularity does affect functional 293 trait patterns of edaphic island plant species by promoting persistence strategies aimed at 294 successfully maintaining viable populations and, at the same time, preventing their local 295 extinction (Auffret et al., 2017; Ottaviani et al., 2020).

\section{High degrees of insularity select for similar persistence strategies}

298 We found support for an insularity effect selecting lower variation in trait values, showing 299 that edaphic island specialists tended to share similar persistence strategies (H2). Indeed, 300 higher degrees of insularity consistently reduced the range of persistence-related trait values 301 and strategies in a given island, i.e. functional diversity, similarly to what is predicted for 302 species richness (Ibanez et al., 2018; MacArthur \& Wilson, 1967; Warren et al., 2015). This 303 is further reinforced not only by single trait diversity patterns but also by patterns concerning 304 multi-trait and Raunkiaer life form, traits which can be considered proxies for the 305 multifunctional island persistence syndrome, at least for the non-acquisitive dimension 
306 examined here (Ottaviani et al., 2020). These findings were further supported by the evidence 307 that these patterns were revealed across all three edaphic island systems, yet with varying 308 strength depending on the degree of the insularity within each system: in fens, there was a 309 stronger and widespread effect on functional diversity patterns (and more marked in 310 specialists species compared to matrix-derived species), whereas in outcrops and 311 mountaintops, this effect was weaker and less pronounced (although our inference power for 312 mountaintops was limited).

314 Insularity as a selective force: the way forward and drawbacks

315 Taken together, our findings suggest that insularity (measured by isolation, island size and 316 target effect) can select traits related to plant persistence, forcing species towards adaptive 317 strategies appointed to prevent local extinction (Auffret et al., 2017). In fact, our work 318 pinpoints how insularity would act as a selecting force by sorting clonal (and non-clonal) 319 species from the broader species pool (according to classic island biogeography predictions); 320 promoting adaptive persistence strategies in terms of trait means (i.e. enhanced abilities to 321 persist locally and therefore avoid local extinction); and fine-tuning those strategies towards 322 lower diversity values (i.e. similar values shared across species); see Figure 2. Indeed, 323 insularity appears to exert its effect on multiple facets of biological diversity, such as trait 324 averages and functional diversity of persistence strategies in edaphic island systems. We 325 propose to call this process "insularity forcing" on island plant forms and functions - in 326 parallel to what is termed "regional forcing" for plant species diversity and composition on 327 islands (Ibanez et al., 2018).

328 As any study, our research has its own limitations, and we acknowledge that other 329 abiotic and biotic factors may affect the observed functional trait patterns. In particular, other 330 environmental variables associated with geology, topography and climate may affect habitat 331 diversity, and thereby species composition and plant functional traits (Lavorel \& Garnier, 332 2002), confounding the aforementioned "insularity forcing". However, having explored the 333 trait-insularity links for both edaphic island specialist and matrix-derived species, we have 334 accounted for possible spurious patterns, and therefore the relationships revealed here can be 335 considered plausible and robust. Yet, future studies may specifically disentangle and quantify 336 the conjoint effect of insularity and other environmental factors on persistence-related 337 functional traits and ideally including other biodiversity facets that may be affected by 338 insularity, such as phylogeny. Ecological and historical settings across habitats and regions 
339 may also provide differences in the insularity forcing, although our results suggest that some

340 persistence traits respond in a similar way across different study systems.

\section{Conclusions}

343 The functional island biogeography approach applied here allowed us to detect the effect of 344 insularity on biota as well as being useful in capturing varying degrees of insularity. Indeed, 345 we can infer that the strongest effect of insularity on functional traits was found in fens, 346 implying that this system operates more similarly to true islands than outcrops and 347 mountaintops do. This was exemplified by the number of significant trait-insularity 348 relationships, the strength of these relationships, and the differences with matrix-derived 349 species patterns, which were always stronger and more marked in fens than in outcrops and 350 mountaintops (similarly to what was found for specialist species richness in Mendez-Castro 351 et al., in press). Our findings also contribute to the ongoing debate on whether terrestrial 352 island-like systems (including edaphic islands) should be considered insular like true islands, 353 namely whether they are ruled by comparable eco-evolutionary forces as true islands (Itescu, 354 2019; Jiménez-Alfaro et al., 2021; Patiño et al., 2017). Our work consistently pinpoints how 355 insularity may affect plant species diversity, distribution, and forms not only on true islands 356 (Burns, 2019; Carlquist, 1974) but also in terrestrial-island like systems (such as the studied edaphic islands), and can determine plant abilities to persist locally.

358 Ultimately, we highlight that insularity - defined as a single (island size, isolation) or 359 combined predictor (target effect) - may operate like a forcing process selecting for adaptive 360 strategies (in terms of trait values and diversity) tailored to promote species ability to avoid 361 local extinction. This biogeographic process may therefore have important implications for 362 the eco-evolutionary dynamics and for the understanding of insular systems' functioning, 363 species coexistence and evolution. We encourage further studies to implement similar 364 functional island biogeographic approaches, possibly extending to other systems (e.g. true 365 oceanic islands) and focusing on different traits (e.g. related to resource acquisition and 366 dispersal ability; Negoita et al., 2016; Schrader et al., 2021; Taylor et al., 2019).

\section{Authors' contribution}

369 GO and LC conceived the research idea and led the writing; MC, MHá, MHo, BJA and DZ 370 provided the vegetation and floristic data and categorised species (specialists and generalists); 371 FEMC measured the insularity metrics; LC gathered plant functional trait data and conducted 
372 all statistical analyses; all authors commented on the methodological approach and the 373 manuscript.

\section{References}

Auffret, A. G., Aggemyr, E., Plue, J., \& Cousins, S. A. O. (2017). Spatial scale and specialization affect how biogeography and functional traits predict long $\square$ term patterns of community turnover. Functional Ecology, 31(2), 436-443. https://doi.org/10.1111/1365-2435.12716

Biddick, M., Hendriks, A., \& Burns, K. C. (2019). Plants obey (and disobey) the island rule. Proceedings of the National Academy of Sciences of the United States of America, 116(36), 17632-17634. https://doi.org/10.1073/pnas.1907424116

Burns, K. (2019). Evolution in isolation: the search for an island syndrome in plants.

$$
\text { Cambridge University Press, Cambridge. https://doi.org/10.1017/9781108379953 }
$$

Carlquist, S. (1974). Island Biology. Columbia University Press, New York.

$$
\text { https://doi.org/10.5962/bhl.title.63768 }
$$

Carter, Z. T., Perry, G. L. W., \& Russell, J. C. (2020). Determining the underlying structure of insular isolation measures. Journal of Biogeography, 47(4), 955-967.

$$
\text { https://doi.org/10.1111/jbi.13778 }
$$

Chytrý, M., Danihelka, J., Kaplan, Z., Wild, J., Holubová, D., Novotný, P., ... Pyšek, P. (2021). Pladias Database of the Czech flora and vegetation. Preslia, 93(1), 1-87. https://doi.org/10.23855/preslia.2021.001

Darwin, C. (1859). On the origins of species by means of natural selection. Murray, London. Díaz, S., Kattge, J., Cornelissen, J. H. C. C., Wright, I. J., Lavorel, S., Dray, S., ... Gorné, L. D. (2016). The global spectrum of plant form and function. Nature, 529(7585), 167171. https://doi.org/10.1038/nature16489

Franklin, J., Keppel, G., Webb, E. L., Seamon, J. O., Rey, S. J., Steadman, D. W., ... Drake, D. R. (2013). Dispersal limitation, speciation, environmental filtering and niche differentiation influence forest tree communities in West Polynesia. Journal of Biogeography, 40(5), 988-999. https://doi.org/10.1111/jbi.12038

Gilpin, M. E., \& Diamond, J. M. (1976). Calculation of immigration and extinction curves from the species area distance relation. Proceedings of the National Academy of 
406 Gower, J. C. (1971). A General Coefficient of Similarity and Some of Its Properties.

407

408

409

410

411

412

413

414

415

416

417

418

419

420

421

422

423

424

425

426

427

428

429

430

431

432

433

434

435

436

437

438

439 Biometrics, 27(4), 857. https://doi.org/10.2307/2528823

Hájek, M., Roleček, J., Cottenie, K., Kintrová, K., Horsák, M., Poulíčková, A., ... Dítě, D. (2011). Environmental and spatial controls of biotic assemblages in a discrete semiterrestrial habitat: comparison of organisms with different dispersal abilities sampled in the same plots. Journal of Biogeography, 38(9), 1683-1693. https://doi.org/10.1111/j.1365-2699.2011.02503.x

Harrison, S., Safford, H. D., Grace, J. B., Viers, J. H., \& Davies, K. F. (2006). Regional and local species richness in an insular environment: serpentine plants in California. Ecological Monographs, 76(1), 41-56. https://doi.org/10.1890/05-0910

Henneron, L., Sarthou, C., de Massary, J., \& Ponge, J. (2019). Habitat diversity associated to island size and environmental filtering control the species richness of rock $\square$ savanna plants in neotropical inselbergs. Ecography, 42(9), 1536-1547. https://doi.org/10.1111/ecog.04482

Herben, T., Šerá, B., \& Klimešová, J. (2015). Clonal growth and sexual reproduction: tradeoffs and environmental constraints. Oikos, 124(4), 469-476. https://doi.org/10.1111/oik.01692

Horsák, M., Hájek, M., Spitale, D., Hájková, P., Dítě, D., \& Nekola, J. C. (2012). The age of island-like habitats impacts habitat specialist species richness. Ecology, 93(5), 11061114. https://doi.org/10.1890/0012-9658-93.5.1106

Horsáková, V., Hájek, M., Hájková, P., Dítě, D., \& Horsák, M. (2018). Principal factors controlling the species richness of European fens differ between habitat specialists and matrix-derived species. Diversity and Distributions, 24(6), 742-754. https://doi.org/10.1111/ddi.12718

Hortal, J., Triantis, K. A., Meiri, S., Thébault, E., \& Sfenthourakis, S. (2009). Island species richness increases with habitat diversity. American Naturalist, 174(6). https://doi.org/10.1086/645085

Ibanez, T., Keppel, G., Baider, C., Birkinshaw, C., Culmsee, H., Cordell, S., ... Birnbaum, P. (2018). Regional forcing explains local species diversity and turnover on tropical islands. Global Ecology and Biogeography, 27(4), 474-486. https://doi.org/10.1111/geb.12712

Itescu, Y. (2019). Are island-like systems biologically similar to islands? A review of the evidence. Ecography, 42(7), 1298-1314. https://doi.org/10.1111/ecog.03951

Jacquet, C., Mouillot, D., Kulbicki, M., \& Gravel, D. (2017). Extensions of Island 
440 Biogeography Theory predict the scaling of functional trait composition with habitat area and isolation. Ecology Letters, 20(2), 135-146. https://doi.org/10.1111/ele.12716

Jiménez-Alfaro, B., Abdulhak, S., Attorre, F., Bergamini, A., Carranza, M. L., Chiarucci, A., ... Winkler, M. (2021). Post-glacial determinants of regional species pools in alpine grasslands. Global Ecology and Biogeography, 30(5), 1101-1115. https://doi.org/10.1111/geb.13274

Jiménez-Alfaro, B., García-Calvo, L., García, P., \& Acebes, J. L. (2016). Anticipating extinctions of glacial relict populations in mountain refugia. Biological Conservation, 201, 243-251. https://doi.org/10.1016/j.biocon.2016.07.015

Kavanagh, P. H., \& Burns, K. C. (2014). The repeated evolution of large seeds on islands. Proceedings of the Royal Society B: Biological Sciences, 281(1786). https://doi.org/10.1098/rspb.2014.0675

Keppel, G., Gillespie, T. W., Ormerod, P., \& Fricker, G. A. (2016). Habitat diversity predicts orchid diversity in the tropical south-west Pacific. Journal of Biogeography, 43(12), 2332-2342. https://doi.org/10.1111/jbi.12805

Kleyer, M., Bekker, R. M., Knevel, I. C., Bakker, J. P., Thompson, K., Sonnenschein, M., ... Peco, B. (2008). The LEDA Traitbase: a database of life-history traits of the Northwest European flora. Journal of Ecology, 96(6), 1266-1274. https://doi.org/10.1111/j.13652745.2008.01430.x

Klimešová, J., Danihelka, J., Chrtek, J., de Bello, F., \& Herben, T. (2017). CLO-PLA: a database of clonal and bud-bank traits of the Central European flora. In Ecology (Vol. 98, p. 1179). Ecological Society of America. https://doi.org/10.1002/ecy.1745

Klimešová, J., Martínková, J., \& Ottaviani, G. (2018). Belowground plant functional ecology: Towards an integrated perspective. Functional Ecology, (May), 2115-2126. https://doi.org/10.1111/1365-2435.13145

Klimešová, J., Martínková, J., Pausas, J. G., de Moraes, M. G., Herben, T., Yu, F. H., ... Ottaviani, G. (2019). Handbook of standardized protocols for collecting plant modularity traits. Perspectives in Plant Ecology, Evolution and Systematics, 40, 125485. https://doi.org/10.1016/j.ppees.2019.125485

Klotz, S., Kühn, I., \& Durka, W. (2002). BIOFLOR-a database on biological and ecological traits of vascular plants in Germany. Schriftenreihe Fur Vegetationskunde, 38, 1-334.

König, C., Weigelt, P., Taylor, A., Stein, A., Dawson, W., Essl, F., ... Kreft, H. (2021). Source pools and disharmony of the world's island floras. Ecography, 44(1), 44-55. https://doi.org/10.1111/ecog.05174 
474

475

476

477

478

479

480

481

482

483

484

485

486

487

488

489

490

491

492

493

494

495

496

497

498

499

500

501

502

503

504

505

506

507

Lavorel, S., \& Garnier, E. (2002). Predicting changes in community composition and ecosystem functioning from plant traits: revisiting the Holy Grail. Functional Ecology, $16,545-556$.

Levin, S. A., Muller-Landau, H. C., Nathan, R., \& Chave, J. (2003). The Ecology and Evolution of Seed Dispersal: A Theoretical Perspective. Annual Review of Ecology, Evolution, and Systematics, 34(1), 575-604. https://doi.org/10.1146/annurev.ecolsys.34.011802.132428

Lomolino, M. V. (2000a). A call for a new paradigm of island biogeography. Global Ecology and Biogeography, 9(1), 1-6. https://doi.org/10.1046/j.1365-2699.2000.00185.x

Lomolino, M. V. (2000b). Ecology's most general, yet protean pattern: The species-area relationship. Journal of Biogeography, 27(1), 17-26. https://doi.org/10.1046/j.13652699.2000.00377.x

Lomolino, M. V., \& Weiser, M. D. (2001). Towards a More General Species-Area Relationship: Diversity on All Islands, Great and Small. Journal of Biogeography, 28(4), 431-445.

MacArthur, R. H., \& Wilson, E. O. (1963). An Equilibrium Theory of Insular Zoogeography. Evolution, 17(4), 373. https://doi.org/10.2307/2407089

MacArthur, R. H., \& Wilson, E. O. (1967). The theory of island biogeography. Princeton University Press.

Mendez-Castro, F., Conti, L., Chytrý, M., Jiménez-Alfaro, B., Hájek, M., Horsák, M., ..., Ottaviani, G. (in press). What defines insularity for plants in edaphic islands? Ecography. https://doi.org/ 10.1111/ecog.05650

Negoita, L., Fridley, J. D., Lomolino, M. V., Mittelhauser, G., Craine, J. M., \& Weiher, E. (2016). Isolation-driven functional assembly of plant communities on islands. Ecography, 39(11), 1066-1077. https://doi.org/10.1111/ecog.01551

Ottaviani, G., Keppel, G., Götzenberger, L., Harrison, S., Opedal, Ø. H., Conti, L., ... Chytrý, M. (2020). Linking Plant Functional Ecology to Island Biogeography. Trends in Plant Science, 25(4). https://doi.org/10.1016/j.tplants.2019.12.022

Ottaviani, G., Martínková, J., Herben, T., Pausas, J. G., \& Klimešová, J. (2017, August 1). On Plant Modularity Traits: Functions and Challenges. Trends in Plant Science. Elsevier Ltd. https://doi.org/10.1016/j.tplants.2017.05.010

Patiño, J., Whittaker, R. J., Borges, P. A. V., Fernández-Palacios, J. M., Ah-Peng, C., Araújo, M. B., ... Emerson, B. C. (2017). A roadmap for island biology: 50 fundamental questions after 50 years of The Theory of Island Biogeography. Journal of 
508

509

510

511

512

513

514

515

516

517

518

519

520

521

522

523

524

525

526

527

528

529

530

531

532

533

534

535

536

537

538

539

540

541

Biogeography, 44(5), 963-983. https://doi.org/10.1111/jbi.12986

Rossetto, M., \& Kooyman, R. M. (2005). The Tension between Dispersal and Persistence

Regulates the Current Distribution of Rare Palaeo-Endemic Rain Forest Flora: A Case Study. Source: Journal of Ecology, 93(5), 906-917. https://doi.org/10.1111/j.13652745.2005.01046.x

Saatkamp, A., Cochrane, A., Commander, L., Guja, L. K., Jimenez-Alfaro, B., Larson, J., ... Walck, J. L. (2019). A research agenda for seed-trait functional ecology. New Phytologist, 221(4), 1764-1775. https://doi.org/10.1111/nph.15502

Schrader, J., Craven, D., Sattler, C., Cámara $\square$ Leret, R., Moeljono, S., \& Kreft, H. (2021). Life $\square$ history dimensions indicate non $\square$ random assembly processes in tropical island tree communities. Ecography, 44(3), 469-480. https://doi.org/10.1111/ecog.05363

Singh, P., Těšitel, J., Plesková, Z., Peterka, T., Hájková, P., Dítě, D., ... Hájek, M. (2019). The ratio between bryophyte functional groups impacts vascular plants in rich fens. Applied Vegetation Science, 22(4), 494-507. https://doi.org/10.1111/avsc.12454

Taylor, A., Weigelt, P., König, C., Zotz, G., \& Kreft, H. (2019, July 1). Island disharmony revisited using orchids as a model group. New Phytologist. Blackwell Publishing Ltd. https://doi.org/10.1111/nph.15776

Violle, C., Navas, M., Vile, D., Kazakou, E., \& Fortunel, C. (2007). Let the concept of trait be functional $\square$ ! Oikos, 116, 882-892. https://doi.org/10.1111/j.2007.0030-1299.15559.x Warren, B. H., Simberloff, D., Ricklefs, R. E., Aguilée, R., Condamine, F. L., Gravel, D., ... Thébaud, C. (2015). Islands as model systems in ecology and evolution: prospects fifty years after MacArthur-Wilson. Ecology Letters, 18(2), 200-217. https://doi.org/10.1111/ele.12398

Weber, L. C., VanDerWal, J., Schmidt, S., McDonald, W. J. F., \& Shoo, L. P. (2014). Patterns of rain forest plant endemism in subtropical Australia relate to stable mesic refugia and species dispersal limitations. Journal of Biogeography, 41(2), 222-238. https://doi.org/10.1111/jbi.12219

Weigelt, P., \& Kreft, H. (2013). Quantifying island isolation - insights from global patterns of insular plant species richness. Ecography, 36(4), 417-429. https://doi.org/10.1111/j.1600-0587.2012.07669.x

Weiher, E., van der Werf, A., Thompson, K., Roderick, M., Garnier, E., \& Eriksson, O. (1999). Challenging Theophrastus: A common core list of plant traits for functional ecology. Journal of Vegetation Science, 10(5), 609-620.

https://doi.org/10.2307/3237076 
542 Westoby, M. (1998). A leaf-height-seed (LHS) plant ecology strategy scheme. Plant and

543 Soil, 199(2), 213-227. https://doi.org/10.1023/A:1004327224729

544 Whittaker, R. J., Fernández-Palacios, J. M., Matthews, T. J., Borregaard, M. K., \& Triantis,

545 K. A. (2017, September 1). Island biogeography: Taking the long view of natures labor

546 atories. Science. American Association for the Advancement of Science.

547 https://doi.org/10.1126/science.aam8326

548 Wright, I. J., Reich, P.B., Westoby, M., Ackerly, D. D., Baruch, Z., Bongers, F., ...Villar, R.

549 (2004). The worldwide leaf economics spectrum. Nature, 428, 821-827.

550 https://doi.org/10.1038/nature02403

551

552 Data accessibility statement

553 Data (insularity metrics and functional indices) will be made fully available through a public 554 repository such as dryad after manuscript acceptance. 


\section{Tables}

558

559 Table 1. List of persistence-related traits included in this study. Trait definition, variable

560 type, units, specific non-acquisitive functions, and source database are reported. Key

561 references related to databases, and trait definitions and their ecological relevance are in the

562 main text.

563

\begin{tabular}{|c|c|c|c|}
\hline Trait name & Definition, variable type and units & Specific function & Source \\
\hline Raunkiaer life form & $\begin{array}{l}\text { Categories identified based on bud location } \\
\text { in the plant body in relation to the soil } \\
\text { surface (discrete; nominal) }\end{array}$ & $\begin{array}{l}\text { Multifunctional } \\
\text { persistence strategy }\end{array}$ & $\begin{array}{l}\text { Pladias, Field } \\
\text { observations }\end{array}$ \\
\hline Reproductive type & $\begin{array}{l}\text { Whether a plant species is capable of } \\
\text { reproducing only sexually, only vegetatively } \\
\text { or both - used to calculate the percentage of } \\
\text { clonal species on each island (discrete; } \\
\text { nominal) }\end{array}$ & Reproductive type & $\begin{array}{l}\text { BiolFlor, Field } \\
\text { observations }\end{array}$ \\
\hline Seed mass & Weight of the seed (continuous; $\mathrm{mg}$ ) & $\begin{array}{l}\text { On-spot persistence; } \\
\text { Dispersal ability }\end{array}$ & LEDA \\
\hline $\begin{array}{l}\text { Size of the } \\
\text { belowground bud bank }\end{array}$ & $\begin{array}{l}\text { Total number of buds stored in belowground } \\
\text { bud-bearing organs per individual } \\
\text { (continuous; number) }\end{array}$ & Resprouting ability (vigor) & CLO-PLA3 \\
\hline $\begin{array}{l}\text { Depth of the } \\
\text { belowground bud bank }\end{array}$ & $\begin{array}{l}\text { Location of the bud bank below the soil } \\
\text { surface (continuous; } \mathrm{cm} \text { ) }\end{array}$ & $\begin{array}{l}\text { Resprouting ability (bud } \\
\text { protection) }\end{array}$ & CLO-PLA3 \\
\hline $\begin{array}{l}\text { Type of clonal growth } \\
\text { organ }\end{array}$ & $\begin{array}{l}\text { Organs dedicated to clonal growth (discrete; } \\
\text { nominal) }\end{array}$ & $\begin{array}{l}\text { Space occupancy; } \\
\text { Resource sharing }\end{array}$ & CLO-PLA3 \\
\hline $\begin{array}{l}\text { Persistence of the } \\
\text { clonal growth organ }\end{array}$ & $\begin{array}{l}\text { Period of connection between offspring } \\
\text { individuals and parental individual in clonal } \\
\text { plants (continuous; year) }\end{array}$ & $\begin{array}{l}\text { Space occupancy; } \\
\text { Resource sharing }\end{array}$ & CLO-PLA3 \\
\hline Lateral spread & $\begin{array}{l}\text { Distance between offspring individuals and } \\
\text { parental individual in clonal plants } \\
\text { (continuous; mm/year) }\end{array}$ & Space occupancy & CLO-PLA3 \\
\hline
\end{tabular}


1 Table 2. Models output for the proportion of clonal specialist species in the edaphic island systems. Each column represents a different model 2 having one single insularity metric as a predictor. Bold text indicates a relevant statistic (significant coefficient and/or $\mathrm{R}^{2} \geq 0.10$ ). All predictors 3 are mean-centered and scaled by 1 standard deviation. $* * * \mathrm{p}<0.001 ; * * \mathrm{p}<0.01 ; * \mathrm{p}<0.05$.

4

\begin{tabular}{|c|c|c|c|c|c|c|c|c|c|}
\hline & \multicolumn{3}{|c|}{ FENS } & \multicolumn{3}{|c|}{ OUTCROPS } & \multicolumn{3}{|c|}{ MOUNTAINTOPS } \\
\hline & Island size & Isolation & Target effect & Island size & Isolation & Target effect & Island size & Isolation & Target effect \\
\hline Coefficient & $8.86 * * *$ & $-7.66 * * *$ & $-9.43 * * *$ & $10.38 * *$ & -5.50 & $\mathbf{- 8 . 8 9} *$ & $3.95 * *$ & 2.46 & $-0.04 *$ \\
\hline Standard Error & $(1.32)$ & (1.47) & $(1.23)$ & (3.01) & (3.66) & $(3.26)$ & $(1.26)$ & $(1.41)$ & $(0.02)$ \\
\hline $\mathrm{R}^{2}$ & 0.49 & 0.37 & 0.56 & 0.40 & 0.11 & 0.29 & 0.30 & 0.12 & 0.16 \\
\hline
\end{tabular}

5 
1 Table 3. Models output for average functional trait values (trait names in italics). Each

2 column reports a summary for a different model, each having one single insularity metric as a 3 predictor. Bold text indicates an important model output (significant coefficient and/or $\mathrm{R}^{2} \geq$ $40.10)$. All predictors are mean-centred and scaled by 1 standard deviation. *** $\mathrm{p}<0.001$; ** $5 \mathrm{p}<0.01 ; * \mathrm{p}<0.05$.

\begin{tabular}{|c|c|c|c|c|c|c|}
\hline \multirow[b]{2}{*}{ Seed mass } & \multicolumn{3}{|c|}{ FENS } & \multicolumn{3}{|c|}{ OUTCROPS } \\
\hline & $\begin{array}{l}\text { Model Island } \\
\text { size }\end{array}$ & $\begin{array}{l}\text { Model } \\
\text { Isolation }\end{array}$ & $\begin{array}{l}\text { Model Target } \\
\text { effect }\end{array}$ & $\begin{array}{c}\text { Model } \\
\text { Island size }\end{array}$ & $\begin{array}{c}\text { Model } \\
\text { Spatial } \\
\text { isolation } \\
\end{array}$ & $\begin{array}{c}\text { Model Targe } \\
\text { effect }\end{array}$ \\
\hline Coefficient & 0.02 & 0.01 & -0.00 & -0.02 & 0,01 & 0.01 \\
\hline Standard Error & $(0.01)$ & $(0.01)$ & $(0.01)$ & $(0.01)$ & $(0.01)$ & $(0.01)$ \\
\hline $\mathrm{R}^{2}$ & 0.03 & 0.00 & 0.00 & 0.12 & 0.01 & 0.05 \\
\hline \multicolumn{7}{|c|}{$\begin{array}{l}\text { Size of the } \\
\text { belowground bud bank }\end{array}$} \\
\hline Coefficient & -0.26 & 0.30 & $0.33 *$ & -0.04 & 0.18 & 0.18 \\
\hline Standard Error & $(0.16)$ & $(0.16)$ & $(0.15)$ & $(0.48)$ & $(0.48)$ & $(0.48)$ \\
\hline $\mathrm{R}^{2}$ & 0.06 & 0.07 & 0.09 & 0.00 & 0.01 & 0.01 \\
\hline \multicolumn{7}{|c|}{$\begin{array}{l}\text { Depth of the } \\
\text { belowground bud bank }\end{array}$} \\
\hline Coefficient & $-0.08 * *$ & 0.04 & $0.07 * *$ & -0.06 & 0.11 & 0.13 \\
\hline Standard Error & $(0.02)$ & $(0.02)$ & $(0.02)$ & $(0.10)$ & $(0.10)$ & $(0.10)$ \\
\hline $\mathrm{R}^{2}$ & 0.19 & 0.06 & 0.14 & 0.02 & 0.06 & 0.08 \\
\hline \multicolumn{7}{|c|}{$\begin{array}{l}\text { Persistence of the } \\
\text { clonal growth organ }\end{array}$} \\
\hline Coefficient & -0.00 & 0.01 & 0.01 & 0.05 & -0.06 & -0.07 \\
\hline Standard Error & $(0.03)$ & $(0.03)$ & $(0.03)$ & $(0.04)$ & $(0.04)$ & $(0.04)$ \\
\hline $\mathrm{R}^{2}$ & 0.00 & 0.00 & 0.00 & 0.07 & 0.09 & 0.13 \\
\hline \multicolumn{7}{|l|}{ Lateral spread } \\
\hline Coefficient & $-0.03 *$ & $0.04 *$ & $0.04 * *$ & -0.05 & 0.05 & $0.06 *$ \\
\hline Standard Error & $(0.01)$ & $(0.01)$ & $(0.01)$ & $(0.03)$ & $(0.03)$ & $(0.03)$ \\
\hline $\mathrm{R}^{2}$ & 0.10 & 0.12 & 0.15 & 0.13 & 0.17 & 0.26 \\
\hline
\end{tabular}

6 
9 Table 4. Models output for functional diversity (trait names in italics). Each column reports a

10 summary for a different model summary, each having one single insularity metric as a

11 predictor. Bold text indicates an important model output (significant coefficient and/or $\mathrm{R}^{2} \geq$

$120.10)$. All predictors are mean-centered and scaled by 1 standard deviation. $* * * \mathrm{p}<0.001$; **

$13 \mathrm{p}<0.01 ; * \mathrm{p}<0.05$.

\begin{tabular}{|c|c|c|c|c|c|c|c|c|c|}
\hline \multirow[b]{2}{*}{$\begin{array}{l}\text { Raunkiaer } \\
\text { life form }\end{array}$} & \multicolumn{3}{|c|}{ FENS } & \multicolumn{3}{|c|}{ OUTCROPS } & \multicolumn{3}{|c|}{ MOUNTAINTOPS } \\
\hline & $\begin{array}{l}\text { Model } \\
\text { Island } \\
\text { size }\end{array}$ & $\begin{array}{l}\text { Model } \\
\text { Isolation }\end{array}$ & $\begin{array}{c}\text { Model } \\
\text { Target } \\
\text { effect }\end{array}$ & $\begin{array}{c}\text { Model } \\
\text { Island } \\
\text { size }\end{array}$ & $\begin{array}{c}\text { Model } \\
\text { Isolation }\end{array}$ & $\begin{array}{l}\text { Model } \\
\text { Target } \\
\text { effect }\end{array}$ & $\begin{array}{c}\text { Model } \\
\text { Island } \\
\text { size }\end{array}$ & $\begin{array}{c}\text { Model } \\
\text { Isolation }\end{array}$ & $\begin{array}{l}\text { Model } \\
\text { Target } \\
\text { effect }\end{array}$ \\
\hline Coefficient & $0.01 * *$ & $-0.01 *$ & $-0.01 * *$ & 0.01 & -0.01 & -0.01 & $0.07 * *$ & -0.00 & $-0.04 *$ \\
\hline $\begin{array}{l}\text { Standard } \\
\text { Error }\end{array}$ & $(0.00)$ & $(0.00)$ & $(0.0042)$ & $(0.01)$ & $(0.01)$ & $(0.01)$ & $(0.02)$ & $(0.02)$ & $(0.02)$ \\
\hline $\mathrm{R}^{2}$ & 0.16 & 0.09 & 0.16 & 0.14 & 0.06 & 0.13 & 0.35 & 0.00 & 0.16 \\
\hline \multicolumn{10}{|l|}{ Seed mass } \\
\hline Coefficient & $0.11 * * *$ & $-0.09 * *$ & $-0.12 * * *$ & -0.02 & 0.01 & 0.02 & & & \\
\hline $\begin{array}{l}\text { Standard } \\
\text { Error }\end{array}$ & $(0.03)$ & $(0.03)$ & $(0.03)$ & $(0.01)$ & $(0.01)$ & $(0.01)$ & & & \\
\hline $\mathrm{R}^{2}$ & 0.29 & 0.19 & 0.30 & 0.13 & 0.03 & 0.08 & & & \\
\hline \multicolumn{10}{|l|}{$\begin{array}{l}\text { Size of the } \\
\text { belowground } \\
\text { bud bank }\end{array}$} \\
\hline Coefficient & $0.54 *$ & $-0.68 * *$ & $-0.73 * * *$ & -0.14 & -0.09 & -0.03 & & & \\
\hline $\begin{array}{l}\text { Standard } \\
\text { Error }\end{array}$ & $(0.21)$ & $(0.21)$ & $(0.21)$ & $(0.43)$ & $(0.43)$ & $(0.43)$ & & & \\
\hline $\mathrm{R}^{2}$ & 0.12 & 0.19 & 0.22 & 0.01 & 0.00 & 0.00 & & & \\
\hline \multicolumn{10}{|l|}{$\begin{array}{l}\text { Depth of the } \\
\text { belowground } \\
\text { bud bank }\end{array}$} \\
\hline Coefficient & $0.16 * *$ & $-0.17 * * *$ & $-0.19 * * *$ & -0.09 & 0.05 & 0.08 & & & \\
\hline $\begin{array}{l}\text { Standard } \\
\text { Error }\end{array}$ & $(0.05)$ & $(0.05)$ & $(0.05)$ & $(0.10)$ & $(0.10)$ & $(0.10)$ & & & \\
\hline $\mathrm{R}^{2}$ & 0.18 & 0.21 & 0.27 & 0.04 & 0.01 & 0.03 & & & \\
\hline \multicolumn{10}{|l|}{$\begin{array}{c}\text { Type of } \\
\text { clonal } \\
\text { growth } \\
\text { organ }\end{array}$} \\
\hline Coefficient & $0.02 * * *$ & $-0.02 * *$ & $-0.02 * * *$ & $0.01 *$ & -0.01 & $-0.01 *$ & & & \\
\hline $\begin{array}{l}\text { Standard } \\
\text { Error }\end{array}$ & $(0.01)$ & $(0.01)$ & $(0.01)$ & $(0.00)$ & $(0.00)$ & $(0.00)$ & & & \\
\hline $\mathrm{R}^{2}$ & 0.22 & 0.20 & 0.28 & 0.28 & 0.12 & 0.27 & & & \\
\hline \multicolumn{10}{|l|}{$\begin{array}{l}\text { Persistence } \\
\text { of the clonal } \\
\text { growth } \\
\text { organ }\end{array}$} \\
\hline Coefficient & -0.00 & -0.02 & -0.01 & 0.05 & 0.00 & -0.01 & & & \\
\hline $\begin{array}{l}\text { Standard } \\
\text { Error }\end{array}$ & $(0.03)$ & $(0.03)$ & $(0.03)$ & $(0.05)$ & $(0.05)$ & $(0.05)$ & & & \\
\hline $\mathrm{R}^{2}$ & 0.00 & 0.01 & 0.00 & 0.05 & 0.00 & 0.01 & & & \\
\hline \multicolumn{10}{|l|}{$\begin{array}{l}\text { Lateral } \\
\text { spread }\end{array}$} \\
\hline Coefficient & $-0.03 *$ & 0.02 & 0.03 & $0.10 * *$ & $-0.07 *$ & $-0.11 * *$ & & & \\
\hline $\begin{array}{l}\text { Standard } \\
\text { Error }\end{array}$ & $(0.02)$ & $(0.02)$ & $(0.02)$ & $(0.03)$ & $(0.03)$ & $(0.03)$ & & & \\
\hline
\end{tabular}


bioRxiv preprint doi: https://doi.org/10.1101/2021.05.13.444066; this version posted May 15, 2021. The copyright holder for this preprint (which

was not certified by peer review) is the author/funder, who has granted bioRxiv a license to display the preprint in perpetuity. It is made available under aCC-BY-NC-ND 4.0 International license.

\begin{tabular}{ccccccc}
$\mathrm{R}^{2}$ & 0.09 & 0.03 & 0.07 & $\mathbf{0 . 4 2}$ & $\mathbf{0 . 2 2}$ & $\mathbf{0 . 4 5}$ \\
\hline Multiple trait & & & & & & \\
Coefficient & $\mathbf{0 . 0 1} * * *$ & $\mathbf{- 0 . 0 1} * *$ & $\mathbf{- 0 . 0 1} * * *$ & 0.01 & -0.00 & -0.01 \\
$\begin{array}{c}\text { Standard } \\
\text { Error }\end{array}$ & $(0.00)$ & $(0.00)$ & $(0.00)$ & $(0.01)$ & $(0.01)$ & $(0.01)$ \\
$\mathrm{R}^{2}$ & $\mathbf{0 . 2 1}$ & $\mathbf{0 . 1 6}$ & $\mathbf{0 . 2 4}$ & $\mathbf{0 . 1 6}$ & 0.01 & 0.06 \\
\hline
\end{tabular}

14

15

16

17

18

19 
bioRxiv preprint doi: https://doi.org/10.1101/2021.05.13.444066; this version posted May 15, 2021. The copyright holder for this preprint (which

was not certified by peer review) is the author/funder, who has granted bioRxiv a license to display the preprint in perpetuity. It is made available under aCC-BY-NC-ND 4.0 International license.

$21 \quad$ Figure and figure legends

22

23 Figure 1. Geographical location and landscape configuration (inset) of the three terrestrial

24 edaphic island systems in Europe. Black circles indicate the sampled habitat islands, whereas

25 empty circles represent the other (not sampled) islands in the surrounding landscape.

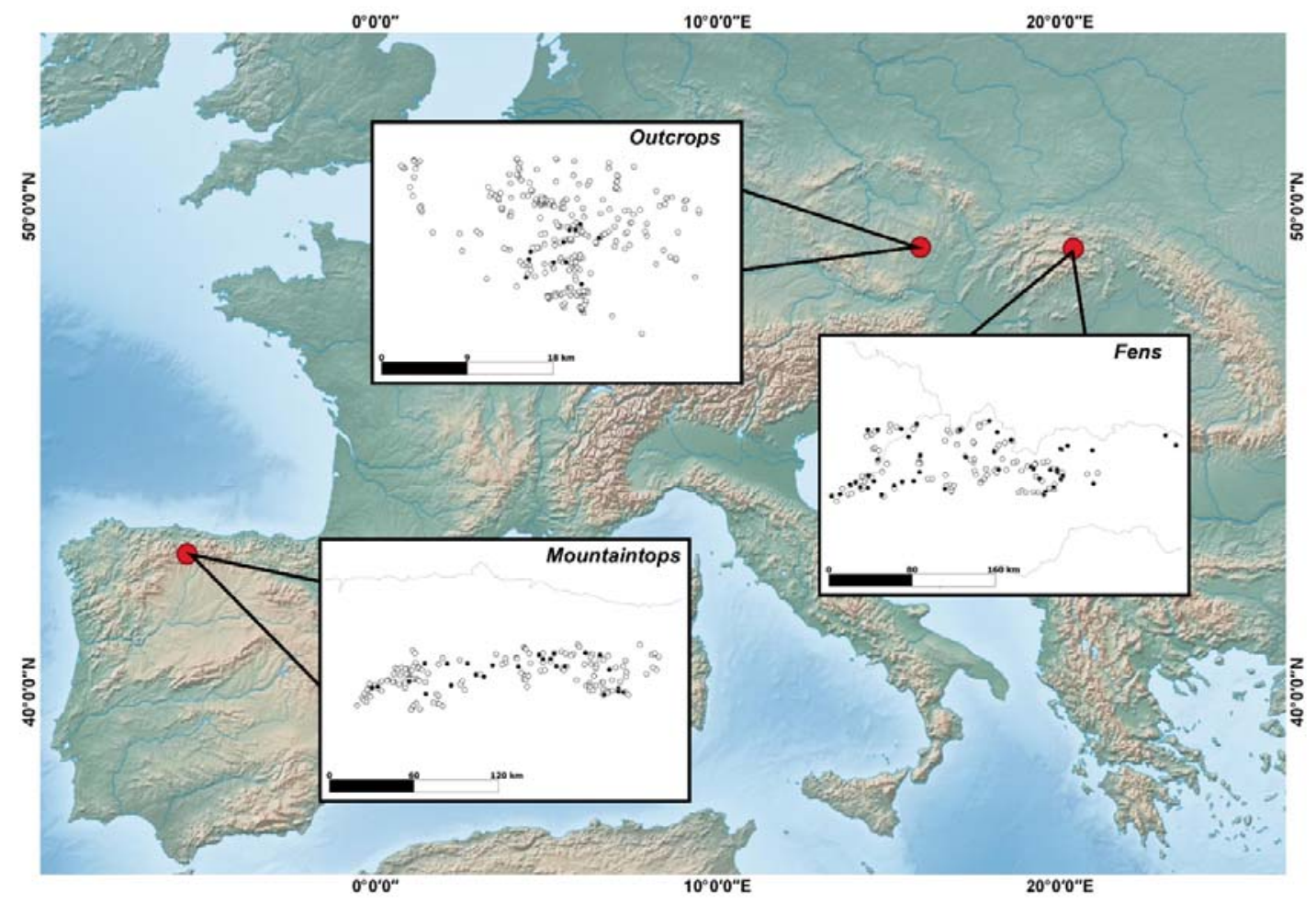


28 Figure 2. Effect plots of selected models, showing the 'insularity forcing', i.e. effect of 29 insularity (target effect) on percentage clonal species, mean trait values (lateral spread

30 distance), and diversity of persistence trait values (type of clonal growth organ) of specialists 31 species in the three edaphic island systems considered.
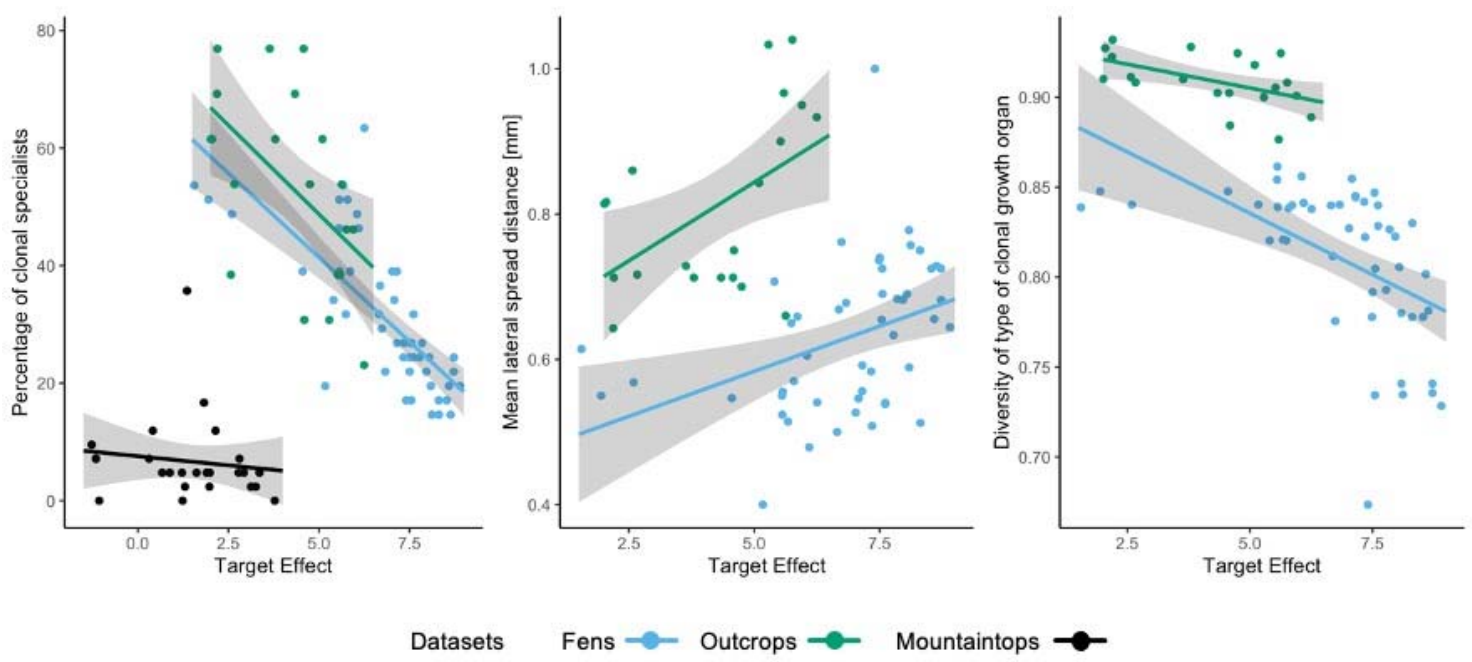

Datasets

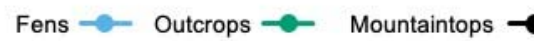

